\title{
ASYMMETRIC PRICE TRANSMISSION AND MARKET \\ CONCENTRATION: AN INVESTIGATION INTO FOUR \\ SOUTH AFRICAN AGRO-FOOD INDUSTRIES
}

\author{
Michela Cutts and Johann Kirsten
}

"Market power is like the wind. You can feel it but you cannot see it"

(Kohls and Uhl 2002, p 270)

\section{INTRODUCTION}

During 2002 and 2003 food prices in South Africa rose dramatically. This followed the combined effect of the sharp depreciation of the Rand against all major currencies and rising world commodity prices. The rise of food prices triggered suspicion about possible manipulation in the agricultural commodity markets, as well as concerns about the concentration and market power in the food manufacturing and retail sector. As a consequence, amongst consumers and Government the perception existed that the role players in the food sector were raising basic food prices unfairly, at the expense of many poor households for which food is a major expenditure.

When the exchange rate improved and commodity prices decreased, the retail prices of most food products were very slow to follow. Once again this strengthened public suspicion about the market power of food manufacturing firms and retail groups.

To verify or reject this public perception, the price formation mechanism in supply chains of basic foodstuffs must be investigated. In such an investigation particular attention should be given to:

- Market power as determined by the level of concentration and the extent of vertical and horizontal integration;

- Price formation at different points in the supply chain;

- Costs and margins at each stage of the value chain.

An investigation into the pricing behaviour of food supply chains must however also consider the changing nature of the agricultural and food industry worldwide, which to a large extent has also been replicated in South Africa. Essentially, this means that supply chains of vertically related oligopolies have emerged either through ownership, strategic alliances, or contractual relationships. The challenge for governments is therefore to ensure that potential social welfare losses resulting from the misallocation of resources and possible abuse of market power are avoided.

In this new agro-food structure the transmission of prices between vertical stages of the supply chain are likely to happen via proprietary information. This entails missing market price information, which, in turn, makes an investigation into anticompetitive behaviour difficult. At the same time, the potential benefits of the new 
agro-food structures should not be ignored. Amongst others, the benefits include potential efficiency gains through reduction of transaction costs and minimizing wastage.

As agricultural products move beyond the farm gate and commodity markets, the costs of value-adding (processing, packaging, distribution) become critical aspects in influencing the retail price of food products. These factors are often influenced by different commodity markets, exchange rates, and in South Africa by State-created monopolies such as Telkom, Sasol, Transnet and Eskom.

As mentioned earlier, given the generally proprietary nature of information in the food manufacturing industry, it is rather difficult to determine which specific aspects are responsible for the increase of the margin between the farm gate and retail prices. In the absence of such detailed information a useful alternative is to analyse the price transmission process along the supply chain. Usually this analysis yields a good reflection of the actions of market participants at different levels.

In this paper we analyse four of the major agro-food supply chains in South Africa. The aim of the analysis is to determine the degree of asymmetric price transformation within these chains. These findings should highlight the degree of uncompetitive behaviour and concentration in the chains. The agro-food supply chains we investigate are (1) the maize to maize meal chain, (2) wheat-to-bread chain, (3) sunflower seed to cooking oil, and (4) the fluid milk chain.

The next section reviews the literature on asymmetric price transmission. This informs the methodology used in this study, which is further described in section 3. Section 4 describes the data used in the analysis, and section 5 contextualises the analytical work by giving an overview of the structure of each of the different supply chains/markets. The last section provides the results of the study.

\section{ASYMMETRIC PRICE TRANSMISSION}

Price is the primary mechanism by which various levels of the market are linked. The extent of adjustment and speed with which shocks are transmitted among producer, wholesale, and retail market prices reflects the actions of market participants at different levels. Over the past decades, producers, consumers, food industry interest groups and legislators have been concerned about the efficiency and equity of price transmission of agricultural and food products. Both casual and empirical research indicates that there are several asymmetries in price transmission in food marketing chains, that is (1) changes in farm and wholesale prices are not fully or more than fully transmitted to consumer prices; (2) changes in consumer prices are not related to short-run changes in farm prices but follow medium- and long-run changes in farm prices with a lag; and (3) downstream changes in consumer prices show a longer time lag than upstream changes do (Abdulai (2002); Azzam (1999); Bunte and Peerlings (2003); Goodwin and Holt (1999); Miller and Hayenga (2001); Von Cramon-Taubadel (1998)) Several possible explanations can be provided to explain this asymmetry depending on the market structure and the nature of the product.

Of the three asymmetries, the one that appears to be of particular interest is the asymmetry in the adjustment process, which indicates whether retailers do pass 
on price increases, while price decreases are only partially passed on to the consumer. From the studies listed previously, it appears that this is particularly the case with agricultural products. One of the reasons that price increases are passed on to the consumer faster than decreases is because firms react faster to decreases in profit margins than they do with regard to increases. Another reason for these asymmetric price adjustments is the presence of search costs in local imperfect markets. For example, grocery stores and other retailers may enjoy local market power because other, similar firms in a given neighbourhood do not exist. This entails that although customers may theoretically have a number of choices, they may in practice not be able to gather full information about prices offered by other firms further away due to the cost involved in doing such a search. It may well happen that consumers observe a price increase at one local retail outlet but are uncertain whether other retail stores have also increased their prices. Given this scenario, firms will respond quickly by raising their prices when upstream prices rise and slowly decrease prices when upstream prices decline.

Another possible source of asymmetric price transmission is market power. Generally, supply chains for food products are less concentrated at the farm gate level than at higher levels because economies of scale will limit the number of viable role-players in a given market. Oligopolistic processors might, for example, react collusively much faster to shocks that squeeze their profit margin than to shocks that stretch it. The same can also happen if individual firms believe that competitors will match increases in output prices as input costs increase, but do not react in the same way as input costs decrease.

To test for asymmetric price transmission there are several different methods available to the researcher. The most widely used method for testing market power and asymmetric price transmission in the agricultural economics literature is the time-series model. This model is based on the assumption that the agricultural product included in the production process is the largest cost component of the final consumer good. This is an important assumption since the higher the cost component, the more direct the effect of increases and decreases of farm prices on retail prices as fewer other cost components come into play. Thus, the question being investigated is whether increases and decreases in farm prices are reflected in, or transmitted to, selling or retail prices. To do this tests for asymmetric price transmission that are consistent with cointegration, are applied to the transmission of commodity prices to retail prices for several goods.

\section{METHODOLOGY}

Testing for asymmetry in price transmission in agricultural markets has been fairly wide-spread, with greatly varying results. Hahn (1990), Hansmire and Schertz Willett (1992) and Kinnucan and Forker (1987) found asymmetric vertical price transmission in the US beef and pork markets, the New York State apple market, and the US dairy market respectively. Boyd and Brorsen (1988) however found no asymmetry in price transmission in the US pork market, 
while Zang, Fletcher and Carley (1995) found asymmetry in the short run but not in the long run in the peanut to peanut butter market in the US. The majority of the studies on asymmetric price transmission apply a variation of a technique introduced by Wolffram (1971) and modified by Houck (1977). This method states that the retail price $\mathrm{P}_{\mathrm{r}}$ responds to the commodity price $\mathrm{P}_{\mathrm{c}}$ according to the following equation:

$\sum_{\mathrm{t}=1}^{\mathrm{n}} \Delta P_{c, t}=\beta_{0}+\beta^{+} \sum_{t=1}^{n} \Delta P_{c, t}+\beta \sum^{\mathrm{n}}{ }_{\mathrm{t} 1} \Delta P^{+}{ }_{t=1} \Delta P_{c, t}+\varepsilon_{\mathrm{n}}$

where $\Delta P^{+}$and $\Delta P^{-}$are the commodity price increases and decreases respectively.

Because $\beta_{0}, \beta^{+}$and $\beta^{-}$are the coefficients, asymmetry is tested by testing if $\beta^{+}=\beta^{-}$. Von Cramon-Taubadel (1996) however found that if this methodology was used and asymmetry was found it was because the regression was spurious or $\mathrm{P}_{\mathrm{r}}$ and $\mathrm{P}_{\mathrm{c}}$ are not cointegrated. Following the above, Von Cramon-Taubadel (1996) proposed the asymmetric error correction representation. In this representation, instead of the price change being segmented into a positive or negative change, the error correction term $\mathrm{ECT}_{\mathrm{t}-1}$ is segmented into $\mathrm{ECT}+$ and ECT-. The original Engel Robert and Granger (1987) specification in equation (2) contained one error correction term $\mathrm{ECT}_{\mathrm{t}-1}$.

$\Delta P_{r, \mathrm{t}}=\beta_{0}+\beta \backslash \Delta P_{C, \mathrm{t}}+\beta_{2} E C T_{t-1}+\beta_{3}(L) \Delta P_{r, t-1}+\beta_{4}(L) \Delta P_{C, t-1}+\varepsilon_{\mathrm{t}}$

In order to test for asymmetry, Granger and Lee (1989) and again Von CramonTaubadel (1996) proposed segmenting the ECT term in (2) into ECT+ and ECT — to yield equation (3).

$$
\Delta P_{r, t}=\beta_{0}+\beta_{1} \Delta P_{c, t}+\beta_{2}^{+} E C T_{t-1}^{+}+\beta_{2}^{-} E C T_{t-1}+\beta_{3}(L) \Delta P_{r, t-1}+\beta_{4}(L) \Delta P_{c, \mathrm{t}-1}+\varepsilon_{\mathrm{t}}
$$

Now the null hypothesis of symmetry is: $\beta_{2}^{+}=\beta_{2}$.

The estimation procedure for the asymmetric error correction model can be summarized as follows:

1. Granger causality tests based on Granger (1969) are performed to test that farm prices "cause" retail prices.

2. Augmented Dicky and Fuller (1979) (ADF) and Phillips and Perron (1988) tests are performed on all the time series to determine the order of integration.

3. A long run cointegration equation is estimated with retail price as the dependent variable and commodity price (with various lags in some cases) as the independent variable.

4. The error term of the above model needs to be stationary for a cointegrating relationship to exist, thus ADF tests are performed on the error terms. 
5. The errors from the cointegrating relationship are divided into two series (ECT+ and ECT-), one for positive errors and one for negative errors

6. The above-generated series are used to define the error correction terms; and the error correction model is then estimated using the Engel-Granger two-step approach using ordinary least squares.

7. The results of the above model are used to estimate an impulse response function.

8. First a $10 \%$ increase in the commodity price in an arbitrary month is run through the model and a new series of expected retail prices is estimated.

9. The difference in the "shocked" price and actual price is then calculated and plotted on a graph.

10. Steps 8 and 9 are repeated for a $10 \%$ decrease in the commodity price in the same month.

$\mathrm{ECT}+$ indicates that the retail price is "too high" compared to the commodity price, i.e. the margin is above its long run equilibrium value. The opposite holds for ECT-. When the coefficient of the ECT- is greater in absolute terms then $\mathrm{ECT}+$, the retail price reacts faster when the profit margin is squeezed than when the profit margin is expanded. Note that only commodity prices are used to estimate the models and no other costs are included, as they would affect the $\mathrm{ECT}+$ and ECT-terms.

\section{DATA}

The products investigated in this article include maize meal, bread, cooking oil, fresh milk, and long life milk. The commodity prices used in this study are the South African Futures Exchange (SAFEX) white maize nearest month contract, the SAFEX sunflower nearest month contract, the SAFEX wheat nearest month contract, and the milk producer price as reported by the National Department of Agriculture; all consumer prices are from the AC Nielsen data base. Retail consumer prices were used due to the lack of availability of wholesale prices of the above products. The time series used are the monthly prices for the period January 2000 to December 2003.

As stated previously, the cost of the primary input as a percentage of the total cost is important in determining the degree of price transmission. The table below reports the average percentage of the total cost of the primary input for each of the above-mentioned products. It is important to note that these are average percentages for reason that commodity prices fluctuate more than the cost of other inputs.

\section{Table 1. Raw materials' percentage of total cost}

$\begin{array}{lc}\text { Wheatflour cost per loaf of bread } & \text { Percentage of total cost } \\ \text { Maize cost per 10kg bag of maize meal } & 45 \% \\ \text { Sunflower seed cost per 750ml cooking oil } & 60 \% \\ \text { Cost of milk per liter of fresh milk } & 72 \% \\ \text { Cost of milk per liter of long life milk } & 60 \% \\ \text { Note: These are average costs for the period January } & 2000 \text {-December } 2003 .\end{array}$




\section{AN OVERVIEW OF THE MARKET STRUCTURE OF THE FOUR AGRO-FOOD INDUSTRIES}

In order to interpret the analytical results correctly, it is important to briefly review the structure of the various agricultural supply chains under investigation. Before doing so it is worthwhile pointing out that the 5 main supermarket chains control $66 \%$ of the food retail market in South Africa (Planet Retail, 2006) and could therefore in various ways effect the price transmission process.

\section{(a) The maize to maize meal supply chain}

The maize to maize meal supply chain is made up of four main stakeholders: the farmers, the silo or storage industry, the milling industry, and the retail sector. As is the case with most farming sectors, the maize sector in South Africa is not concentrated. It has approximately 9000 farmers planting 3.4 million hectares of maize. The storage and milling industries show a certain degree of concentration, which arose naturally from many years of a single channel controlled marketing system. The grain storage capacity in South Africa is approximately 17.5 million tons, $85 \%$ of which is in the hands of 22 silo owners. Three of the above silo owners control $70.3 \%$ of the total grain storage capacity. Even though the number of informal millers has increased rapidly since deregulation, the situation in the milling industry is not very different from that of the storage industry: $73 \%$ of the market share is held by four companies.

\section{(b) The wheat to bread supply chain}

There are currently between 5000 and 6000 wheat farmers in South Africa who produce on average 2 million tons per year. Demand regularly outstrips supply, causing a shortfall, which is then imported. The wheat to bread supply chain is similar to that of the maize meal supply chain with the exception that there is an additional 'step' in the supply chain, namely, the baking industry. While the number of small-scale millers and bakers has expanded since deregulation, the industrial large-scale millers and bakers still have the largest market share in the production and sale of bread. The four main wheat millers, Genfoods, Pioneer Foods, Tiger Brands, and Ruto Mills currently control approximately $87 \%$ of the market. Most of the major mills are vertically integrated with plant bakeries. In South Africa there are approximately 7900 bakeries (these include stand alone, instore, and franchise bakeries). Of these 85 are wholesale bakeries.

\section{(c) The sunflower to cooking oil supply chain}

Because maize and sunflower are substitutes for each other, it is estimated that the number of sunflower farmers is similar or possibly slightly lower than that of maize farmers. The eight largest seed crushing plants crush the bulk of the South African sunflower seed crop. There are 13 oil refineries; seven of these are vertically integrated with crushing plants. South Africa does not produce enough oil seeds to meet the demand for cooking oil. To meet the demand crude oil is imported rather than oil seeds. This fact, together with the fact that there is a substantial underutilization of the oil crushing capacity, forces the industry to become more competitive.

\section{(d) The milk producer to fresh and long life milk supply chain}

The milk output of approximately 5000 dairy farmers is sold in an oligopolistic market. There are about 13 milk buyers, of which the largest four process roughly $65 \%$ of the total commercial milk delivered to dairies. Of these four, the 2 main dairy processors, namely Clover SA and Parmalat, are also the price leaders when it comes to purchasing milk 
Table 2. Estimates of the asymmetric Error Correction Model

\begin{tabular}{|c|c|c|}
\hline Dependent & Independent Variable & Coefficient \\
\hline \multirow[t]{6}{*}{ Maize meal } & Constant & 0.929 \\
\hline & SAFEX WHITE MAIZE & $0.339 *$ \\
\hline & $\mathrm{ECT}+$ & $-0.188 * *$ \\
\hline & ECT- & $-0.491 *$ \\
\hline & $\mathrm{R} 2$ & 0.837 \\
\hline & Residual Sum of Squares & 0.167 \\
\hline \multirow[t]{6}{*}{ Bread } & Constant & -2.077 \\
\hline & SAFEX wheat & $0.431 *$ \\
\hline & ECT + & $-0.178 * *$ \\
\hline & ECT- & $-0.285^{* *}$ \\
\hline & R2 & 0.502 \\
\hline & Residual Sum of Squares & 0.214 \\
\hline \multirow{6}{*}{ Cooking oil } & Constant & -3.896 \\
\hline & SAFEX sunflower & $0.739 *$ \\
\hline & $\mathrm{ECT}+$ & $-0.446 * *$ \\
\hline & ECT- & $-0.249 * *$ \\
\hline & $\mathrm{R} 2$ & 0.889 \\
\hline & Residual Sum of Squares & 0.292 \\
\hline \multirow[t]{6}{*}{ Fresh milk } & Constant & 1.668 \\
\hline & Milk producer price & $0.849^{*}$ \\
\hline & $\mathrm{ECT}+$ & $-0.120 * *$ \\
\hline & ECT- & $-0.114 * *$ \\
\hline & $\mathrm{R} 2$ & 0.932 \\
\hline & Residual Sum of Squares & 0.507 \\
\hline \multirow[t]{6}{*}{ Long life milk } & Constant & 0.891 \\
\hline & Milk producer price & $1.023^{*}$ \\
\hline & $\mathrm{ECT}+$ & $-0.241 * *$ \\
\hline & ECT- & $-0.711^{*}$ \\
\hline & $\mathrm{R} 2$ & 0.918 \\
\hline & Residual Sum of Squares & 0.091 \\
\hline
\end{tabular}

$$
*=\text { Significant at } 5 \%, \quad * *=\text { significant at } 10 \%
$$

A similar situation exists at the retail level where most dairy products are sold through supermarkets and hypermarkets. In other words, there is oligopolistic competition at both the retail and processing levels of the milk market. 


\section{RESULTS}

Granger causality tests (Granger 1969) were performed on all the products. It was found that all retail prices are "caused" by the farm prices and not vice versa. According to the ADF and Phillips-Perron tests the null hypothesis of difference stationarity cannot be rejected as all the price series are integrated of order one I(1). Altogether the results confirm the existence of asymmetry in all the supply chains investigated in this study. All the ECT terms, both positive and negative, are significantly less than 1, which indicates that retail prices do not react completely within one month to the relevant producer price (see Table 2). This lag in responsiveness could be caused by the existence of wholesale prices - that are not captured in this study; it also indicates however that monthly data is frequent enough to find evidence of the price transmission process.

In all cases, except for cooking oil and fresh milk, ECT- is greater than ECT+. This means that when the margin is below the long run equilibrium, retail prices react faster and to a greater extent than when margins are above the long run equilibrium. In other words, when margins are squeezed they react faster than when they are stretched.

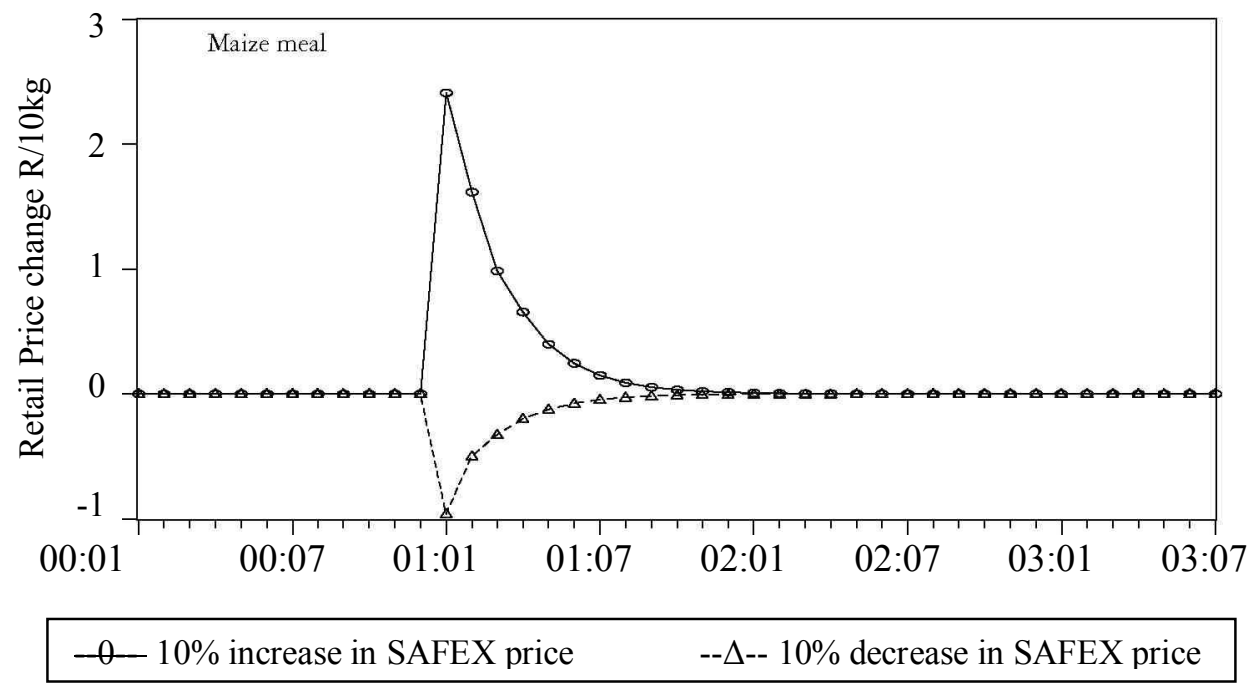

Figure 1. The effect of a 10\% price increase/decrease of the SAFEX nearest month maize contract on the retail price of $10 \mathrm{~kg}$ maize meal

This is, however, not so in cooking oil and fresh milk prices. These two products are quite different from the other products, in terms of the supply chain and the type of consumer product itself. Therefore there are different reasons why the retail prices of these products reacted as they did.

Although the dairy industry is fairly concentrated on the processing side, fresh milk is a highly perishable product. This entails that if prices were to increase too rapidly, retailers might face a risk that the stock remaining on the shelf turns sour. As a consequence producer price increases are not as readily passed onto the consumer as producer price decreases. This is of course not the case for long life milk. 
The cooking oil situation is, however, quite different from that of milk, as cooking oil is not a very perishable product. Although the sunflower oil industry is concentrated on the crushing side, it is not a concentrated industry because South Africa does not produce enough oil to satisfy demand. Sunflower oil is therefore often imported, and if the domestic price were to rise above import parity, imports would as a result increase.

Are the above asymmetries economically meaningful? With the above models it is possible to simulate the effect that price shocks at the commodity level have on the retail level. To illustrate the effect of asymmetry on retail prices, a $10 \%$ increase in the SAFEX nearest month contract was simulated; and subsequently a $10 \%$ decrease in price was simulated in the same month. The "shock" was simulated for one month only, after which it was assumed that prices returned to normal. Subtracting the simulated retail prices from the actual prices shows how prices are likely to change and how long it will take for them to return to normal. In the case of maize and maize meal, the upward price "shock" resulted inaR2.42 increase per $10 \mathrm{~kg}$ bag of maize meal that took 8 monthstoreturntonormal.The downward "shock" resulted in a R0.95 decrease in the $10 \mathrm{~kg}$ maize meal retail price that returned to its normal level in only 5 months. Thus price increases are passed on to the consumer to a larger extent than price decreases. The above is illustrated by Fig. 1.

The above simulation was repeated for the other three industries. A $10 \%$ price increase and decrease was applied to the SAFEX wheat nearest month contract, the SAFEX sunflower nearest month contract, and to the milk producer price. The effect of these "shocks" was recorded and the results are shown in Fig. 2, 3, and 4 below.

In the case of the wheat to bread supply chain the ECT coefficients are significantly different from unity. This implies that bread retail prices do not react completely within one month to changes in the SAFEX wheat price. As a result, monthly data are frequent enough to expose the process of price transmission. The coefficient of ECT- is larger than that of ECT+, thus ECT- induces a greater change in retail price than ECT+. ECTindicates that the retail price is too low compared to the SAFEX wheat price and as a result the margin is below the long run equilibrium. Thus retail prices react more rapidly when margins are squeezed than when they are stretched. ECT + is not significantly different from zero; thus when margins are stretched, there is no significant change in the retail price to reduce such a margin.

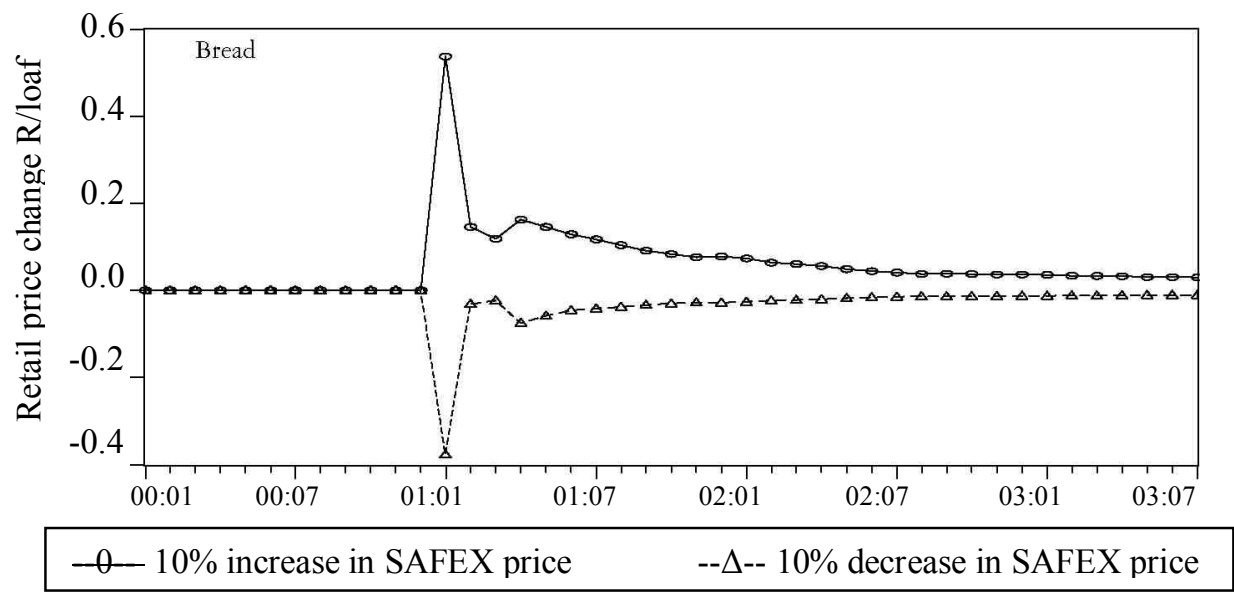

Figure 2. The effect of a 10\% price increase/decrease of the SAFEX nearest month wheat contract on the retail price of a loaf of brown bread 


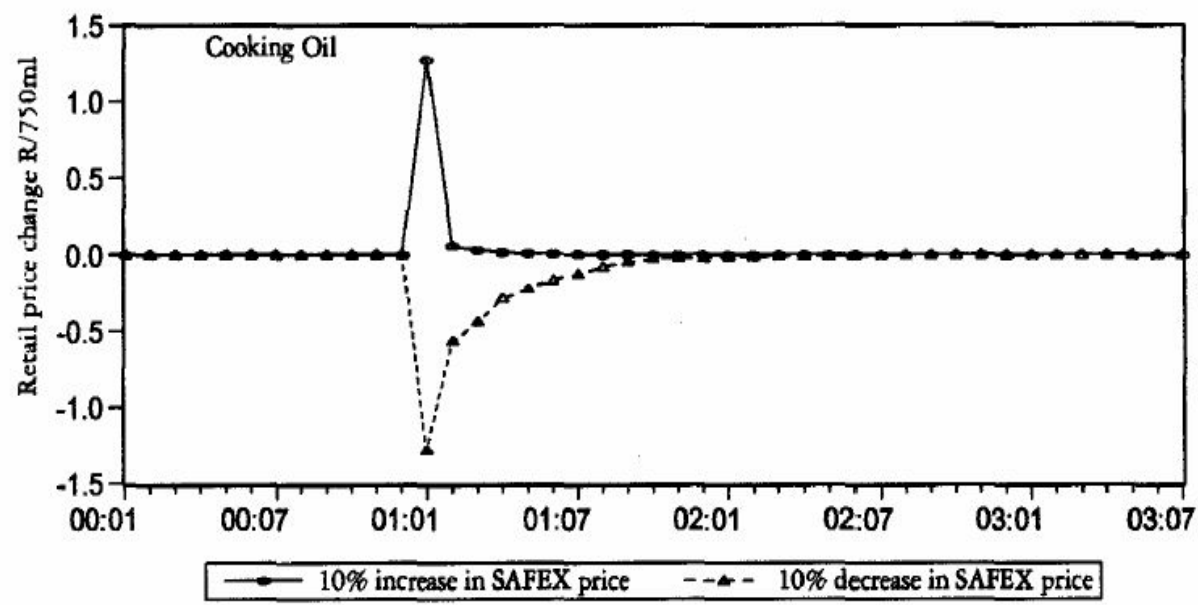

Figure 3. The effect of a 10\% price increase/decrease of the SAFEX nearest month sunflower contract on the retail price of a $750 \mathrm{ml}$ bottle of cooking oil

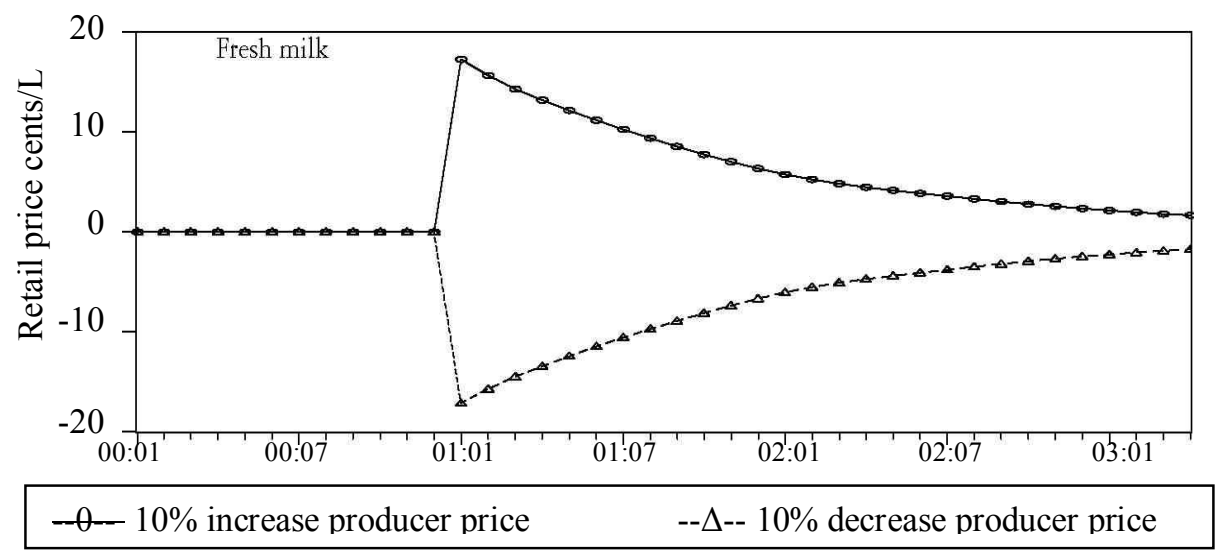

Figure 4. The effect of a 10\% price increase/decrease of the producer price of milk on the retail price of 1 liter of fresh milk

A $10 \%$ increase in the SAFEX wheat nearest month contract will result in a price increase of R0.53 per loaf, which decreases to R0.14 per loaf after one month. The remaining increase will take 20 months to be worked out of the system. Similarly a $10 \%$ decrease in the SAFEX nearest month contract will result in a R0.37 per loaf decrease in the retail price of bread. This decrease drops to only R 0.03 per loaf after one month. The effect of the decrease in price will take 15 months to be eliminated.

As stated previously the asymmetric price transmission in the cooking oil and fresh milk industries are quite different from those of the maize meal and bread industries. In these two industries the change in retail price after the commodity price shock is almost the same regardless whether the shock is up or down. 
The amount of time it takes for the respective shocks to be eliminated from the system differs, with the decrease in price being felt for longer than the increase in price. Thus, a $10 \%$ increase/decrease in the SAFEX sunflower nearest month contract would result in a $\mathrm{R} 1.27$ increase/decrease in the price of $750 \mathrm{ml}$ bottle of cooking oil. The price increase is felt for only 4 months while the price decrease is felt for 11 months.

The fresh milk price transmission is similar to that of cooking oil. A $10 \%$ increase/decrease in the producer price of milk would result in a R0.17 increase/decrease in the retail price of 1 liter of fresh milk. The price increase takes 20 months to be eliminated from the system while the price decrease has an effect on the retail price for 22 months.

Price transmission from commodity level to retail level is affected not only by the degree of competition within an industry but also by the nature of the product. The results above indicate that when industries are not very competitive due to high levels of market concentration, commodity price increases have a larger effect on the retail price than price decreases do, and the effect is felt for a longer period. The dynamics however are quite different if the product is highly perishable. The effect of market concentration appears to be overridden by the fact that the product is perishable, which results in the price transmission being closer to that of a competitive market.

\section{CONCLUSION}

From our analyses it follows that in agro-food industries with some market concentration there is a high level of asymmetric price transmission. This, however, is considerably lower when the retail product is perishable. The results concur with a priori expectations that retailers and/or processors respond more rapidly when their margins are squeezed than when they are stretched. The ability of processors and retailers to "delay" passing on certain price changes depends among other things on their market power. The presence of asymmetric price transmission does not necessarily mean the existence of market power and concentration at some level of the supply chain. In the case of South Africa, however, when we compare the price transmission of the different markets, it is clear that the more the market is concentrated the higher is the level of asymmetry.

Although this analysis has succeeded in showing that concentrated markets have a higher level of asymmetric price transmission than markets that are not concentrated, there is much room for further research on this topic. We suggest that this type of analysis be done at each level of the supply chain to determine where prices are "sticking", and whether, in fact, market power is to blame for the presence of asymmetric price transmission.

\section{REFERENCES}

ABDULAI, A. (2002). Using threshold cointegration to estimate asymmetric price transmission in the Swiss pork market. Applied Economics, 34(6): 679-691.

AZZAM, A. M. (1999). Asymmetry and rigidity in farm-retail price transmission. American Journal of Agricultural Economics, 81(3): 525-534.

BOYD, S. M. and BRORSEN, B. W. (1988). Price asymmetry in the US pork marketing channel. North Central Journal of Agric Economics, 10: 103-110.

BUNTE, F. and PEERLINGS, J. (2003). Asymmetric price transmission due to market power in the case of supply shocks. Agribusiness, 19(1): 19-28.

DICKEY, D. A. and FULLER W. A. (1979). Distribution of the estimators for autoregressive time series with a unit root. Journal of the American Statistical Association, 74: 427-431.

ENGLE ROBERT, F. and GRANGER, C. W. J. (1987). Co-integration and error correction: representation, estimation, and testing. Econometrica, 55: 251-276.

GOODWIN, B. K. and HOLT, M. T. (1999). Price transmission and asymmetric adjustment in the US beef sector. American Journal of Agricultural Economics, 81(3): 630-638. 
GRANGER, C. W. J. (1969). Investigating causal relationships by econometric models and crossspectral methods. Econometrica, 37: 424-438.

GRANGER, C. W. J. and LEE, T. H. (1989). Investigation of production, sales and inventory relationships using multicointegration and non-symmetric error correction models. Journal of Applied Econometrics, 2: 111-120.

HAHN, W. F. (1990). Price transmission asymmetry in pork and beef markets. The Journal of Agricultural Economics Research, 42: 21-30.

HANSMIRE, M. R. and SCHERTZ WILLET, L. (1992). Price transmission processes: A study of price lags and asymmetric price response behavior for New York Red Delicious and Mcintosch apples, Cornell University.

HOUCK, J. P. (1977). An approach to specifying and estimating non-reversible functions. American Journal of Agricultural Economics, 59: 570-572

KINNUCAN, H. W. and FORKER, O. D. (1987). Asymmetry in farm-retail price transmission for major dairy products. American Journal of Agricultural Economics, 69: 285-292.

KOHLS, R. L. and UHL, J. N. (2002). Marketing of agricultural products, 9th edition. Upper Saddle River, USA: Prentice Hall.

MILLER, D. J. and HAYENGA, M. L. (2001). Price cycles and asymmetric price transmission in the US pork market. American Journal of Agricultural Economics, 83(3): 551-562.

PHILLIPS, P. C. B. and PERRON P. (1988). Testing for a unit root in time series regression. Biometrika, 75: 335-346.

PLANET R. (2006). Country reports: South African grocery retail environment. Accessed on the internet at www.planetretail.net.

VON CRAMON-TAUBADEL, S. (1996). An investigation of non-linearity in error correction representations of agricultural price transmission. Contributed paper, VIII Congress of the European Association of Agricultural Economists, Edinburgh.

VON CRAMON-TAUBADEL, S. (1998). Estimating asymmetric price transmission with the error correction representation: An application to the German pork market. European Review of Agricultural Economics, 25(1): 1-18.

WOLFFRAM, R. (1971). Positivistic measures of aggregate supply elasticities: Some new approaches - some critical notes. American Journal of Agricultural Economics, 53: 356-359.

ZANG, P., FLETCHER, S. M., and CARLEY, D. H. (1995). Peanut price transmission asymmetry in peanut butter. Agribusiness, 11: 13-20. 